
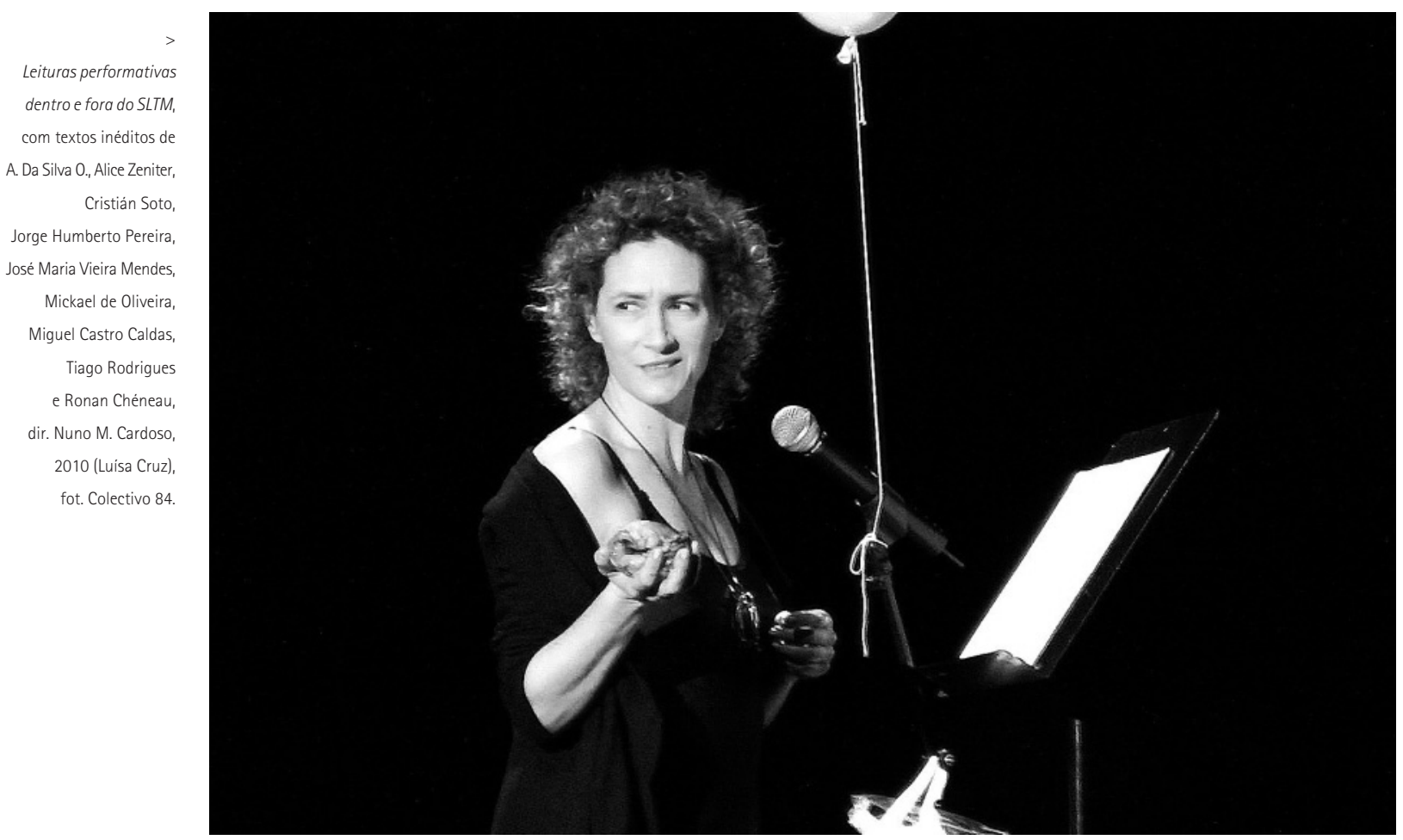

\title{
Encontros de Novas Dramaturgias Contemporâneas 2010
}

\section{Mickael de Oliveira | Diego Barros | Nelson Guerreiro}

\section{Um projecto com nomes e percursos} Mickael de Oliveira

Ninguém, e ainda menos os encenadores, tem o direito de dizer que não há autores. Claro que não os conhecemos, porque não são encenados, e o facto de serem montados hoje e em muito boas condições é considerado uma oportunidade única; quando é, afinal o minimo que se pode fazer. Como querem que os autores se tornem melhores se nada Ihes é pedido e quando não existe a preocupação de tirar deles o seu melhor. Os autores da nossa época são tão bon quanto os encenadores da nossa época.

Bernard-Marie Koltès (apud Ryngaert 1998: 217-218)

em Estudos Artístico - Variante Teatro, pel Faculdade de Letras da

Universidade de

Coimbra e está a

finalizar o seu

doutoramento na área

da dramaturgia

contemporânea

portuguesa e europeia

pela Faculdade de

Letras da Universidade

de Lisboa.

É dramaturgo

dramaturgista e co-

director do Colectivo

84 (Lisboa).
Foi em 2007 que recebi o Prémio Nova Dramaturgia Maria Matos com o texto 0 que é teu entregou aos mortais.

Estava de saída da Faculdade de Letras da Universidade da Coimbra, no último semestre da licenciatura em Estudos Artísticos (variante Teatro) e com vontade de continuar o meu interesse académico sobre a dramaturgia portuguesa contemporânea, contra o espanto de alguns colegas que não viam onde estava a dramaturgia portuguesa, viva. Nessa altura, eu também não via muito bem quais eram os seus contornos. Recebido o prémio, havia a ideia de me mudar para a capital, perante o facto óbvio de que o teatro, num Portugal pouco descentralizado, passava-se em Lisboa, praticamente a única zona do país onde se poderia averiguar a existência de uma "comunidade teatral". Nesse mesmo ano, inscrevi-me na Faculdade de Letras da
Universidade de Lisboa com vista a preparar um doutoramento que teria por base um levantamento, mapeamento e reflexão sobre a dramaturgia portuguesa do pós-25 de Abril. Nesse mesmo Verão, antes de começa a rentrée escolar, participei enquanto observador num festival de dramaturgia contemporânea, em Pont-àMousson - La Mousson d'Été, sob direcção de Michel Didyme. Entretanto, o texto que havia sido premiado foi traduzido para francês depois de a Isabel Alves Costa o ter entregue à Marianne Clévy, directora artística da plataforma de partilha de nova dramaturgia europeia Corps de Textes. Participei enquanto autor na edição Corps de Textes 2007, na altura em que o projecto tinha passado em Portugal pelo Porto, no Teatro do Campo Alegre. Comecei muito rapidamente a pensar numa eventual "escala" do projecto em Lisboa suportada pelo recémcriado Colectivo 84, que entretanto havia formado com o John (Romão), em 2008. Aos poucos, fui conhecendo os parceiros da rede Corps de Textes, iniciava em Lisboa o meu doutoramento, descobrindo quem escrevia e quem fazia teatro, digerindo a ideia de um festival de dramaturgia europeia em Lisboa, com a participação e ajuda clara da Isabel. A digestão de um ideário programático para o festival era lenta e acompanhada pelas recordações que me tinha deixado a Mousson d'Été. Entretanto, esperávamos uma resposta importante de Bruxelas (estávamos então em 2009) à candidatura conjunta que tínhamos entregue, com o Théâtre de La Place (Liège, 


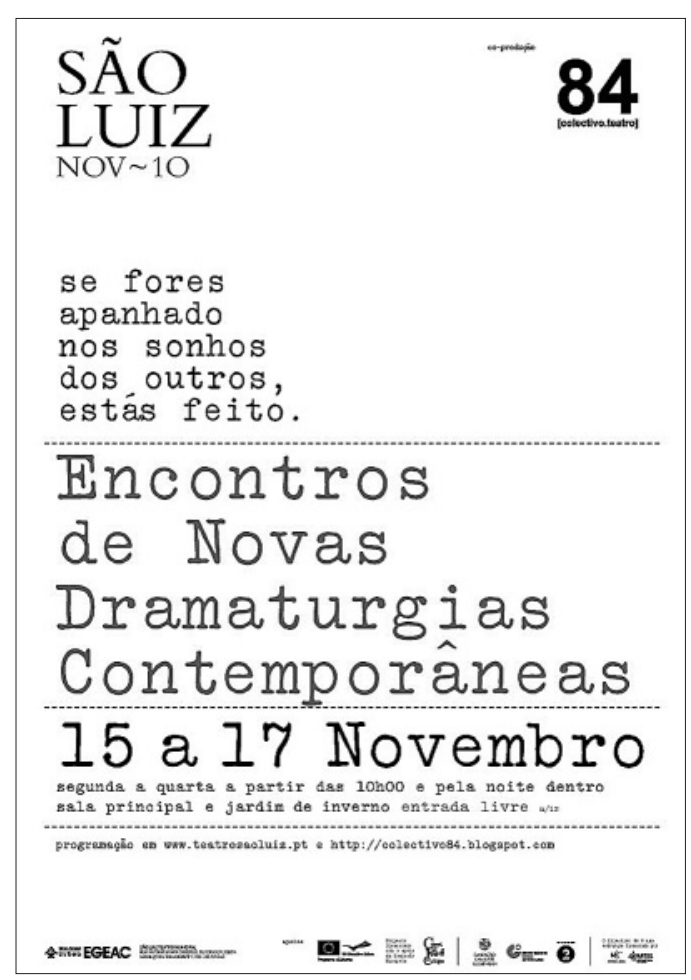

Bélgica), Scène Nationale de Petit-Quevilly Mont-SaintAignant (França) Centro Dramático de Plovdiv (Plovdiv, Bulgária) e o Teatro da Armada Búlgara (Sofia, Bulgária). Tornava-se urgente encontrarmos uma casa para sediar Corps de Textes em Lisboa e ainda mais urgente pensar a programação, sobretudo num contexto português que não possuía nenhuma montra regular em Lisboa para a dramaturgia portuguesa contemporânea. Assim, enquanto pensava na pertinência de alargar o futuro festival de dramaturgia contemporânea a autores portugueses, a Isabel telefonou ao director artístico do São Luiz Teatro Municipal de então, Jorge Salavisa. Recebeu-nos, a mim e ao John, ao lado da Aida (Tavares), para explicarmos o projecto. Tentei explicar a importância de um festival desta natureza, baseado em leituras encenadas, em seminários, debates, oficinas de tradução ${ }^{1}$, bem como sobre a necessidade de criarmos um acontecimento que envolvesse, claro, a comunidade teatral, mas igualmente as escolas profissionais e superiores com cursos em Artes Performativas e Estudos Artísticos de todo o pais, para criar um efectivo projecto educativo. Adiantei ainda que ímos trazer cerca de 60 alunos de todo o país, custeandoIhes as despesas para poderem assistir a este surto de três dias de nova dramaturgia. Apresentei-Ihe alguns autores portugueses e europeus, um orçamento, um desenho de programação com os encenadores que pretendia envolver. 0 Jorge Salavisa mostrou desde logo o seu interesse com entusiasmo, por acreditar em "projectos novos com gente nova". Passado pouco tempo, o Jorge confirmava a nossa presença na sua programação, entregando-nos o Jardim de Inverno e a Sala Principal (com restrições devido a um espectáculo que já lá estava montado), sabendo que passado pouco tempo ser-nosia comunicado o apoio financeiro da Europa. Podia então concretizar a programação.
Após alguns encontros com o John e o Rui Pina Coelho que ajudaram a arrancar com algumas ideias para a programação, surgiu um imperativo para a constituição desta primeira edição: era necessário criar uma espécie de painel da nova dramaturgia portuguesa e da dramaturgia contemporânea nacional, em geral. Para os novos autores (cuja "novidade" remonta ao início do século XXI) pensei encomendar textos breves para contextos / lugares específicos. Lancei um desafio a cada autor, dandoIhe um contexto de escrita: a leitura do texto partilharia um percurso pela cidade com outros textos (leituras em centros comerciais, em lojas abandonadas, nos bombeiros, em museus, etc.), assim como a equipa que iria assegurar a leitura (encenador e a maioria dos actores). Desse modo, deu-se início à linha dramatúrgica que iria sustentar a primeira edição: os escritores / as escritas de palco.

Este conceito que nasce sobretudo na senda da conceptualização do teatro contemporâneo elaborada, em parte, por Hans-Thies Lehmann, foi definido e usado pelo pensador e académico belga Bruno Tackels para caracterizar uma prática de "escrita" que vários artistas partilham, tais como Pippo Delbono, Romeo Castellucci e Rodrigo Garcia. Tackels define as escritas de palco como uma escrita não-dramática (e não exclusivamente literária) em que "o texto provém da cena e não do livro" (Tackels 2007: 2l)

0 momento tornava-se oportuno para convidarmos Tackels com o propósito de "abrir" os três dias do festival que acabaria por ficar com o simples nome de Encontros de Novas Dramaturgias Contemporâneas. 0 mote estava então lançado: a dramaturgia contemporânea é antes de mais uma espécie de literatura aplicada, cujas contingências de grupo e de produção se sobrepõem às necessidades do autor. Assim sendo, pensámos na elaboração de três seminários que poderiam prolongar
'Durante o festival, criámos duas oficinas de tradução, uma de português para alemão, francamente apoiada pelo Goethe Institut de Lisboa, coordenada por Vera San Payo de Lemos e Marianne Gareis, outra de português para francês coordenada por Ilda dos Santos. Salienta-se ainda o trabalho impar que muitos tradutores fizeram para os encontros: todas as traduções do francês para português foram trabalhadas pela Alexandra Moreira da Silva, a tradução do dinamarquês pelo Pedro Fernandes, a do búlgaro pela Zlatka

Timenova-Valtcheva e pela Emilia Yanakieva. Todo este trabalho de tradução, ao qual o John Romão e eu nos juntámos, teve como objectivo traduzir de português para as outras linguas os textos curtos portugueses e estrangeiros encomendados e dois textos de formato longo. 
esse mote para o espaço português e desafiámos três autores para nos contar o modo como escrevem para os seus espectáculos: Carlos Costa (Visões Úteis), Carlos J. Pessoa (Teatro da Garagem) e José Maria Vieira Mendes (Teatro Praga). Longe de uma prática de escrita solipsista esta triade entende que o seu trabalho deve partir da elaboração do dispositivo cénico e nutrir-se dos demais materiais, assim como do discurso (estético e político) do colectivo artístico.

Todos os jovens autores estrangeiros que fizeram parte da programação estrearam-se no nosso território, e enquanto que Alice Zeniter [França], Cristián Soto [Chile], Françoise Berlanger [Bélgica], Ronan Chéneau [França], Zachary Karabashliev [Bélgica], nos ofereceram textos curtos (à semelhança dos portugueses), Frédéric Sonntag [França], assim como Christian Lollike [Dinamarca] entregaram-nos textos longos. Como convidados da nova dramaturgia nacional, estiveram presentes autores com regularidade laboral como Ana Mendes, André Murraças, Armando Nascimento Rosa, Miguel Castro Caldas, Tiago Rodrigues, Luís Mestre, Paulo Castro, Pedro Eiras, e eu próprio. E outros mais discretos no panorama nacional dramatúrgico, mas não menos interessantes, como Jorge Humberto Pereira, João Santos Lopes, Da Silva O. Para além das encomendas a esta "nova" geração de criadores, outras figuras ligadas à nossa dramaturgia estiveram presentes, cujos textos foram lidos, tais como Abel Neves, Eduarda Dionísio, Luisa Costa Gomes, Jorge Silva Melo e o já referido Carlos J. Pessoa, entre muitos outros. Além destes últimos autores mais maduros, cujos trabalhos, na sua maioria, marcaram principalmente a década de $80 \mathrm{e}$ 90 do século passado, outros vieram juntar-se através da abertura de um "concurso para a novíssima dramaturgia", lida na última noite do festival, momento em que conhecemos algumas das novas sensibilidades da escrita teatral, passando a nomear os que foram seleccionados num total de mais de 60 textos recebidos e lidos pelo nosso júri: A. Branco, Cláudia Lucas Chéu, Hugo Siroco, Paulo Castro de Oliveira.

Constaram no projecto mais de vinte e cinco autores vivos portugueses, e vários foram os encenadores e criadores que se associaram, tais como John Romão, Miguel Loureiro, Pedro Gil, Nuno. M. Cardoso, Nelson Guerreiro, Martim Pedroso, Francisco Salgado e Jorge Silva Melo. Associaram-se ainda os imprescindiveis leitores, dezenas de actores profissionais e em formação, que fizeram com que o festival se realizasse em muito boas condições, entre os quais Albano Jerónimo, António Simão António Fonseca, Inês Vaz, João Lagarto, Luisa Cruz, Mónica Garnel, Rita Loureiro, Sandra Roque, Sílvia Filipe, Sylvie Rocha, Teresa Tavares.

Para o leitor, que ainda tenha dúvidas sobre a existência de uma (nova) dramaturgia nacional, poderíamos contra-argumentar a velha ideia garrettiana segundo a qual o nosso país não possui uma tête dramatique. Esta enumeração (a que poderiamos acrescentar muitos outros nomes) dá a sensação de ter havido nestes últimos anos uma espécie de ânimo à volta de autores para a cena. Porém, tais painéis - que originaram e justificam em boa parte a criação de um festival sobre dramaturgia contemporânea - são o fruto de um longo e profundo trabalho que várias estruturas têm feito em torno da dramaturgia contemporânea portuguesa e internacional, citando duas experiências que vale a pena destacar: uma interrompida e sem sucessor, o DRAMAT - Centro de Novas Dramaturgias, projecto sediado no Teatro Nacional São João, organizado por António Mercado, Fernando Mora Ramos e Maria João Vicente, e uma outra dirigida e mantida pelos Artistas Unidos, com direcção de Jorge Silva Melo.

Criado em 1999, o DRAMAT tinha como objectivo principal a produção, divulgação editorial e montagem dos textos de jovens autores que frequentavam o Centro. Adoptando uma postura radical em relação à nova 


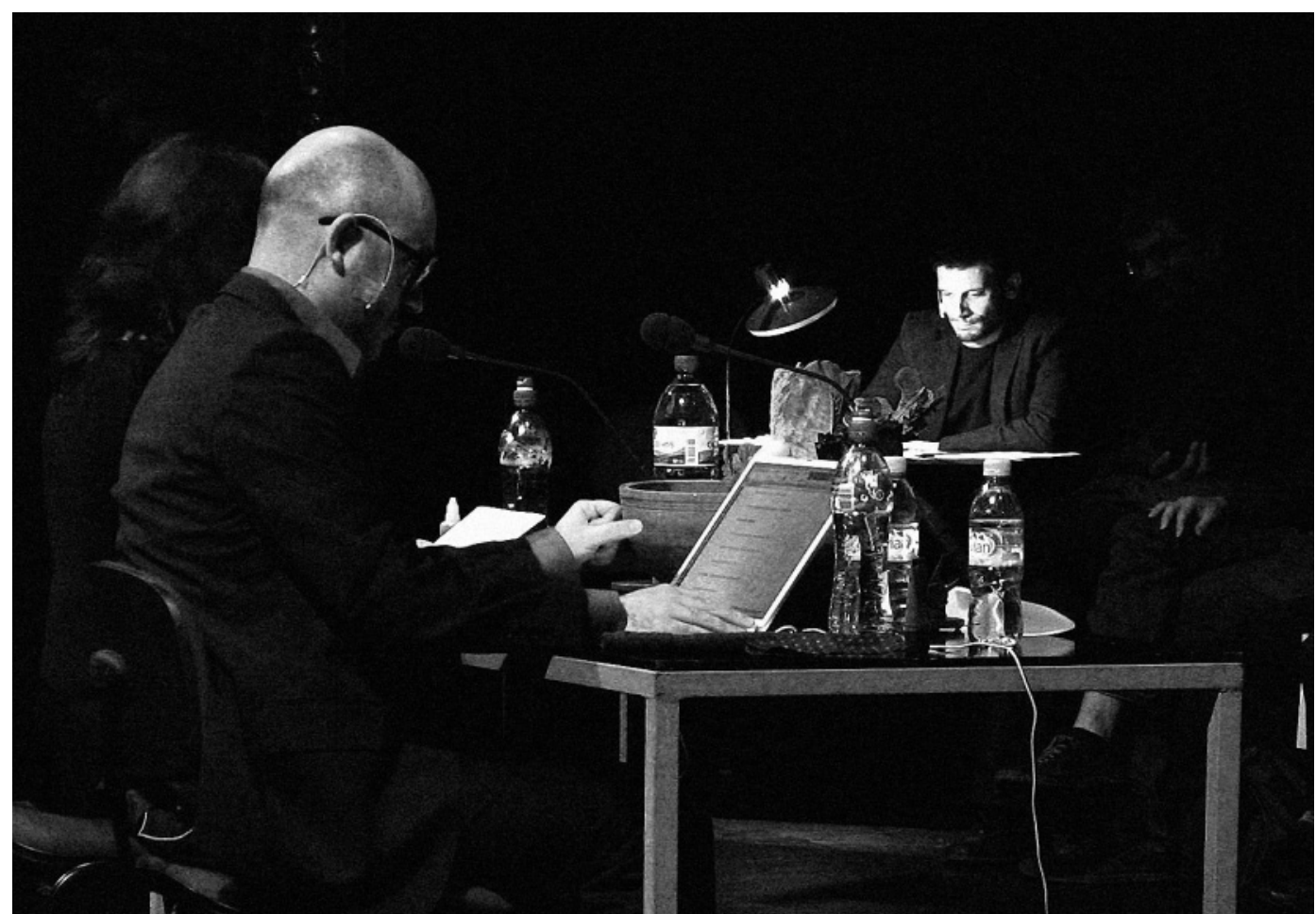

Conferência-Performance Guerrero Notebook: de voyeur a diseur, um olhar agudo sobre os Encontros de Novas Dramaturgias Contemporâneas ou, por outras palavras, sobre tudo aquilo que se disse, mas também sobre tudo aquilo que se disse e não se ouviu e, ainda, sobre tudo aquilo que nunca se disse mas que se vai dizer porque devia ter sido dito e é para ser ouvido, dir. Nelson Guerreiro, 2010

(Ágata Alencoão, Nelson Guerreiro e Martim Pedroso), fot. Colectivo 84.

dramaturgia, o TNSJ de Ricardo Pais apresentou um equilibrio surpreendente no seu repertório entre 1994 e 2004, tendo acolhido na sua sala quase tantos autores pertencentes ao "grande" repertório (indo ao encontro da sua missão de base), como contemporâneos, incluindo portugueses. A dramaturgia portuguesa destacou-se assim no TNSJ como uma caracteristica fundadora do projecto portuense e sinal da importância que a nossa dramaturgia obteve desde então. Jacinto Lucas Pires terá sido o resultado mais visivel desse incentivo, tendo a sua carreira sido impulsionada pelo Nacional do Porto. O DRAMAT, juntamente com o TNSJ, conseguiu apoiar institucionalmente autores que continuam a trabalhar no ramo da dramaturgia até hoje, como acontece com Pedro Eiras ou Jorge Louraço Figueira, entre outros. Quase em simultâneo, em Lisboa, a recém-criada companhia Artistas Unidos, sob os desígnios do seu director, autor, encenador e produtor, Jorge Silva Melo, empreendia um projecto igualmente peculiar dedicado às novas dramaturgias europeias e portuguesas. Se é facto que o repertório dos Artistas Unidos se funda (ainda hoje) na dramaturgia estrangeira de textos escritos, com um intervalo menor em relação à sua montagem portuguesa (à semelhança do Novo Grupo nos anos 80 e 90), Silva Melo, para além de promover o seu próprio trabalho dramatúrgico, deu lugar à escrita de jovens que vieram a tornar-se autores regulares da cena portuguesa, destacando-se claramente José Maria Vieira Mendes. Posto isto, é pertinente observarmos como as instituições têm um papel chave na criação de autores e na legitimação das suas escritas. Os dramaturgos precisam, nos seus textos, não só de palavras assinadas por si, mas da assinatura de outros autores, no sentido foucauldiano, desde a do encenador à do programador/director. Esta acumulação valorativa contempla também um fenómeno que marcou a década de 90 e o início do século XXI, com a criação de pequenas e novas companhias independentes que continham um projecto de dramaturgia de cena (literária ou não) própria, cujos artistas chave constaram em grande parte da nossa programação.

A própria figura do autor-encenador tornou-se uma presença mais visivel no panorama do nosso teatro, presença que a socióloga Vera Borges quantificou. Nos inquéritos empreendidos entre 2000 e 2002 para o seu trabalho, 0 mundo do teatro em Portugal, concluiu que 29\% dos encenadores inquiridos eram simultaneamente os autores da escrita dos seus próprios espectáculos e que 26\% dos actores inquiridos também estavam ligados à dramaturgia dos seus projectos (Borges 2007: 116). Porém, não podemos afirmar de um modo leve que vivemos um periodo próspero no que diz respeito à dramaturgia contemporânea. Num recente estudo que empreendi (Para uma cartografia da criação dramática portuguesa contemporânea [1974-2004]), pude verificar que em 30 anos (1974-2004) de actividade teatral profissional, a dramaturgia portuguesa viva representada pela maior parte das companhias históricas do teatro independente, numa visão de conjunto, havia mantido uma percentagem estável, entre 16\% e 18 \%, em relação ao repertório "clássico" ou contemporâneo estrangeiro dramático e não-dramático. Se, por um lado, devemos olhar com entusiasmo para o terreno que os autores conquistam de projecto em projecto, por outro, não podemos fugir ao reconhecimento da posição "menor" que tem ocupado no seio das companhias que mais financiamento têm tido para a produção teatral. De facto, "menor" seria a palavra que melhor poderia definir a condição da dramaturgia portuguesa contemporânea, indo ao encontro do termo de Gilles Deleuze e Félix Guattari quando caracterizavam a língua/linguagem na obra de Kafka:

A desterritorialização da lingua, a ligação do individual com o imediato político, o agenciamento colectivo da enunciação. 0 mesmo será 
Leitura performativa da novissima dramaturgia

portuguesa,

com textos de A. Branco, Cláudia Lucas Chéu,

Hugo Siroco e Paulo

Castro de Oliveira, direcção de John Romão 2010

(Paulo Castro de Oliveira, Pedro Lacerda,

Silvia Filipe, Cecilia Henriques, Miguel da Cunha, João Lagarto,

A. Branco,

Cláudia Lucas Chéu)

fot. Colectivo 84

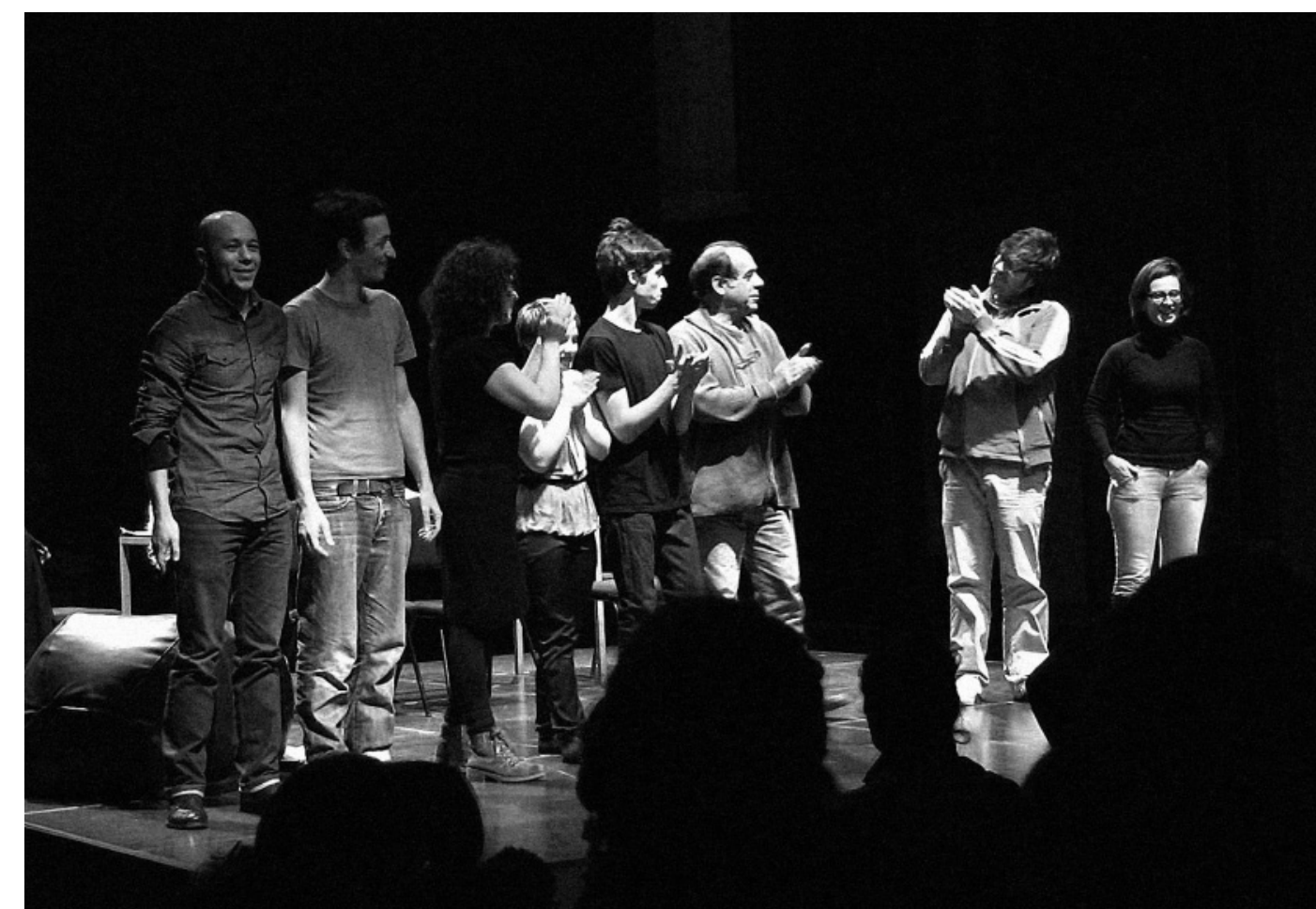

dizer que 'menor' já não qualifica certas literaturas, mas as condições revolucionárias de qualquer literatura no seio daquela a que se chama grande (ou estabelecida) (...) Até aquele que por desgraça nascer no pais de uma grande literatura tem de escrever na sua lingua (...) Escrever como um cão que faz um buraco, um rato que faz a toca. E, por isso, encontrar o seu próprio ponto de subdesenvolvimento. 0 seu patoá, o seu próprio terceiro mundo, 0 seu próprio deserto" (Deleuze / Guattari 2003: 41-42)

\section{Notas sobre o processo de produção Diego Barros}

0 que é novo na fase da cultura de massas em comparacão com a fase do liberalismo avançado é a exclusão do novo. A máquina gir

Diego Barros

é administrador,

formado pela Faculdad

de Ciências da

Administração da

Universidade de

Pernambuco

(Fcap-UPE, Brasil),

mestrando em Estudos de Teatro na Faculdade

de Letras da

Universidade de Lisboa.

Foi o produtor

executivo dos

Encontros de Novas

Dramaturgias

Contemporâneas e do

Ciclo de Nova

Dramaturgia

Portuguesa, realizações

do Colectivo 84

(Lisboa). sem sair do lugar. Ao mesmo tempo que já determina o consumo,

ela descarta o que ainda não foi experimentado porque é um risco. (Adorno / Horkheimer 1943: 63)

Acredito que, no âmbito da chamada indústria cultural contemporânea, os projectos artísticos devem reflectir cada vez mais o posicionamento dos criadores diante dos desafios impostos pelo contexto. Desta maneira, cada acção proposta será a materialização de uma insatisfação particular, em função do carácter deficitário do que já é o panorama socio-económico que permeia o marco-zero de qualquer proposta. Para que isto seja formulado de maneira sólida, um dos caminhos pode ser a observância do seguinte conceito: de que um projecto cultural deve ser, desde o inicio, um reflexo da integração, entre o aspecto demonstrativo-financeiro formal e as pretensões artísticas em plena concepção. Isto sem que o primeiro aspecto estrangule uma ideia mas sim que seja uma estrutura potencializadora das acções ainda intencionadas, para que o espírito inquieto da proposta artística se projecte, como protagonista que é, e encontre seus respectivos ecos no entorno. $\mathrm{Ou}$, num contexto mais desfavorável, que sirva de base para que a ideia original seja transmutada em algo que ao mesmo tempo seja possivel realizar, e que respeite os objectivos iniciais. Para que este procedimento seja possível, o primeiro passo é a despeito do nosso costume de criar dualidades ou antagonismos, entender que a formalidade demonstrativafinanceira e o conteúdo artístico são formas complementares - ainda que distintas - de formular uma proposta.

$\mathrm{Na}$ concepção do projecto Encontros de Novas Dramaturgias Contemporâneas estes preceitos receberam atenção especial. No intuito de encontrar os já referidos ecos, vários elementos foram cruzados, a começar pela inevitável - e, ainda assim, não-óbvia - localização geográfica. 0 projecto foi realizado no coração do Chiado sediado no São Luiz Teatro Municipal, ocupando também outros locais do bairro. Realizou-se um movimento ciclico que, ao mesmo tempo, apresenta e representa, ou seja, dá a conhecer o espaço ao redor sob diferentes olhares, a partir de possibilidades distintas, mostrando uma conjuntura única de percepções provenientes de autores actores, encenadores, teóricos, tradutores e outros variados intervenientes nacionais e internacionais, através da ênfase clara na dramaturgia portuguesa contemporânea ao longo dos três dias do festival, ocorrido entre os dias 15 e 17 de Novembro de 2010.

Uma vez determinado o seu lugar no espaço, no tempo e o seu corpus criativo preliminar, o passo seguinte foi a percepção das afinidades que esta proposta poderia ter com os objectivos institucionais de diferentes estruturas culturais, no sentido de conceber a rede de cooperação necessária à concretização do evento, fazendo convergir patrocínios dentro de um conceito de viabilidade económica que qualifique o montante disponibilizado pela instituição - seja ela pública ou privada - enquanto um investimento e não uma obrigação de atender o clamor dogmático de incentivo à cultura por si só. Acções como a busca de 
novos públicos - através do subsídio oferecido a mais de 50 alunos oriundos de diferentes universidades do norte ao sul de Portugal -, a concretização de uma plataforma de reflexão teórica e de "encontros" entre diferentes criativos, a utilização de espaços alternativos no bairro do Chiado, as oficinas de traduções - do português para o francês e para o alemão, ocorridas durante o festival -, a possibilidade da edição de publicações bilingues, bem como a perspectiva de internacionalização do projecto, ou seja, todas estas acções, criaram em seu conjunto uma imagem que felizmente inspirou a associação de instituições como a Fundação Calouste Gulbenkian, o Goethe-Institut Portugal, o Corps de Textes Europe estrutura financiada pelo Programa "Cultura" da Comissão Europeia, da qual o Colectivo 84 é um dos associados além do São Luiz Teatro Municipal e a EGEAC, e do Ministério da Cultura e a DGArtes - que apoia esta e outras actividades do Colectivo 84. Desde o princípio o intuito era que esta associação não se configurasse de forma apenas pontual, mas que oferecesse um indicativo de continuidade, através não só das próximas edições dos Encontros (que ocorrerão de dois em dois anos), mas também através de acções relacionadas, tal como o Ciclo de Nova Dramaturgia Portuguesa no exterior, que está em pleno processo de produção, estabelecendo parcerias em Berlim, Paris, Rio de Janeiro e São Paulo, entre outras cidades.

A aceitação e a consequente realização deste projecto pioneiro representam uma resposta à consideração feita por Adorno e Horkheimer, citada logo no início. Tal comentário, enquadrado em seu contexto particular, é de facto justificável. No entanto, não deve encontrar legitimidade ou adequabilidade no nosso contexto actual, ou então estaremos condenados à barbárie, comprovando a ineficácia das nossas acções perante um destino imutável. Aqui a intenção sempre foi - e sempre será - a de provar justamente o contrário.

\section{Um balanço com duas de mão} Nelson Guerreiro

Este texto recorda, em breves palavras, o que terão sido estes Encontros - não longe do que entendemos como actos performativos -, mas não chega a ser uma cobertura total dos acontecimentos. Leia-se, por isso, este "resgate do efémero" a partir de uma vontade de inscrever para não esquecer, mas é sabido como a nossa capacidade de retenção é limitada, ao mesmo tempo que acreditamos que fixar e recordar também é fazer desaparecer.

Para fundamentar a probabilidade multiplicadora do acto discursivo, dever-se-á ter em devida conta as palavras de Peggy Phelan no seu incontornável texto: "Ontologia da performance: Representação sem produção". A autora afirma que, à semelhança da performance, qualquer acto de fala é sempre um novo acto (Phelan 1998: 175). Assim sendo, qualquer descrição de uma qualquer performance não se assemelha nunca à experiência que os espectadores tiveram ao presenciá-la e esta não pode ser reproduzida como um quadro ou uma escultura. Acrescente-se ainda, e através de Phelan, que "tentar escrever sobre o evento indocumentável da performance é invocar as regras do documento escrito e, logo, alterar o evento em si mesmo" (Ibidem:173). Deste modo, a reprodução de uma performance por palavras torna-se numa nova acção e a escrita tem que encontrar uma forma de se tornar ela mesma performativa em vez de descritiva.

Comecemos, então, pelo princípio dos princípios: era uma manhã de Outono: 15 de Novembro de 2010, segunda-feira, 10h39m, à porta do São Luiz Teatro Municipal. A cidade vivia a azáfama e o bulício de uma segunda-feira. Na verdade, à porta do teatro, parecia que estávamos na Islândia. Passo a explicar: a aglomeração de pessoas era semelhante à de uma noite de espectáculo desejado. Podiamos estar a fazer cinema através do efeito day for night (noite americana). Aquela manhã
Nelson Guerreiro

é docente na Escola Superior de Artes e Design das Caldas da Rainha nos cursos de Teatro e Som e Imagem. A partir de 2001 tem desenvolvido o seu trabalho como artistainvestigador em vários projectos individuais $\mathrm{e}$ colectivos no campo da performance, teatro $\mathrm{e}$ dos cruzamentos disciplinares, destacando-se a série de conferênciasperformance Guerrero Notebook, a colaboração com o Teatro Praga, o Mundo Perfeito, a Truta e, mais recentemente, com Martim Pedroso, como dramaturgo e dramaturgista dos seus espectáculos. Desde de 2009 é membro da plataforma de sinergias criativas: sindicato.biz. 
transformar-se-ia, como se estivéssemos numa rodagem numa noite através de um só filtro. Só que havia uma única diferença: eram pessoas que estavam à espera de entrar para dentro do filme e estavam carregadas de mochilas. Depois da obtenção da credencial, os participantes entraram e as portas da sala principal abriram-se para o seminário: "Práticas de escrita para a cena contemporânea portuguesa", orientado por Carlos Costa, das Visões Úteis.

Logo de entrada o criador / orientador propôs fazer uma viagem no tempo pelas escritas teatrais, desde a Antiguidade Grega - que até um determinado momento do século XX se continuam a denominar como escritas dramáticas - até aos nossos dias, mais concretamente até aquele "aqui e agora" que simultaneamente já era "ali e há bocado".

Rewind. As escritas dramáticas, assentes na poética aristotélica, foram apresentadas como "paradigma violento, já que condicionaram a emergência de novas formas."

Fast forward. Segundo Carlos Costa, entre os anos 80 e o principio dos anos 90, existia um sentimento quotidiano de atrofiamento por parte dos autores. Com o fim da Galáxia Gutenberg, termo fascinante cunhado por McLuhan, em que o livro deixa de ser o principal veículo de transmissão e produção de conhecimento, abre-se espaço às novas escritas ligadas muito mais ao processo de criação de um espectáculo. Surgem, então, escritas fragmentadas que desobedeciam à lógica de uma peça "começar no amanhecer e acabar ao pôr-do-sol ou começar por nos dar conta das curvas das montanhas e acabarmos a contemplar as curvas das ondas do mar." Para fundamentar esta nova ordem dramatúrgica a nivel europeu, foi referido Romeo Catellucci que, a este propósito, disse que, finda a criação e depois da sua estreia, se senta na plateia, no escuro, e sente que não sabe mais sobre o espectáculo do que o espectador que está ao seu lado, e que isso the abre a possibilidade de continuar à procura.

Em suma e parafraseando Carlos Costa:

As escritas de cena não fecham a narrativa num aquário, partemno, mas vão à procura de água, para salvar os peixes entretanto moribundos, expondo o falhanço dos modos de reprodução da realidade. Pode correr mal porque os autores sabem que não dominam tudo. Por outro lado e a jusante, é aqui que se opera o cruzamento entre a arte e a vida. Dai a abertura para o tratamento autobiográfico dos temas ser um passo natural, tal como a sua/nossa sede. Eis-nos no cruzamento entre a realidade e a ficção. Ou seja, a realidade é subvertida pela possibilidade de ficção. Ficção de si próprio e mera exposição de autobiografia, outro dos mapas de trabalho, ou melhor, de exploração das novas dramaturgias contemporâneas.

Um dos eixos definidos por Carlos Costa para a escrita de cena era "o desejo de parricídio das grandes referências dramatúrgicas universais e dos modos de produção dominante. A nova dramaturgia descobre-se no processo criativo com todos os elementos nele participantes". Acresce ainda que tudo isto deve ser visto aos olhos da tensão entre a estética e as questões económicas e sociais. Ou seja, às vezes é mais caro fazer de novo, do que fazer com um texto que já existe e que, na maior parte dos casos, já não custa nada, por ser património da Humanidade.

Fast forward. Bruno Tackels, na sua comunicação intitulada "Do texto para palco ao palco como texto", começou por dizer que continuamos a querer responder à pergunta: "Em que é que o teatro pode transformar o mundo?" E respondeu a esta questão essencialista com uma sequência de outras perguntas:

Como é que se fala da Nike? Da deslocalização de empresas? Da mobilidade das pessoas por motivos de discriminação racial? Do norte e do sul? Do consumismo de pacotilha? Da McDonald's? Das Kardashian? Do Cristiano Ronaldo? Da Lady Gaga? Da desvalorização da familia? Das sociedades sem futuro? Dos electrões livres? Da visão da História do nosso país? Das vidas que não se podem ter mas que se querem ter? Da descrença no amor para sempre? Das fantasias recônditas sem magoar a pessoa com quem vivemos? Da possibilidade de seduzir através da escrita? Da possibilidade da criação como um acto de reparação? De uma ideologia que não praticamos? Da vulgaridade da violência? Do mistério da vida? Da arte? Da utilidade ou da sua inutilidade? De levar o teatro ao seu grau zero? Do erro de Descartes e da consciência de si? Da impossibilidade de o tempo falar das suas coisas? Do que gostávamos de ouvir ou de escrever ou de ver feito? Como, quem, porquê?

Antes de fechar o texto, gostaria ainda de reproduzir uma citação de Tackels (integrada na folha de sala) que serviu de mote para a sua intervenção: 


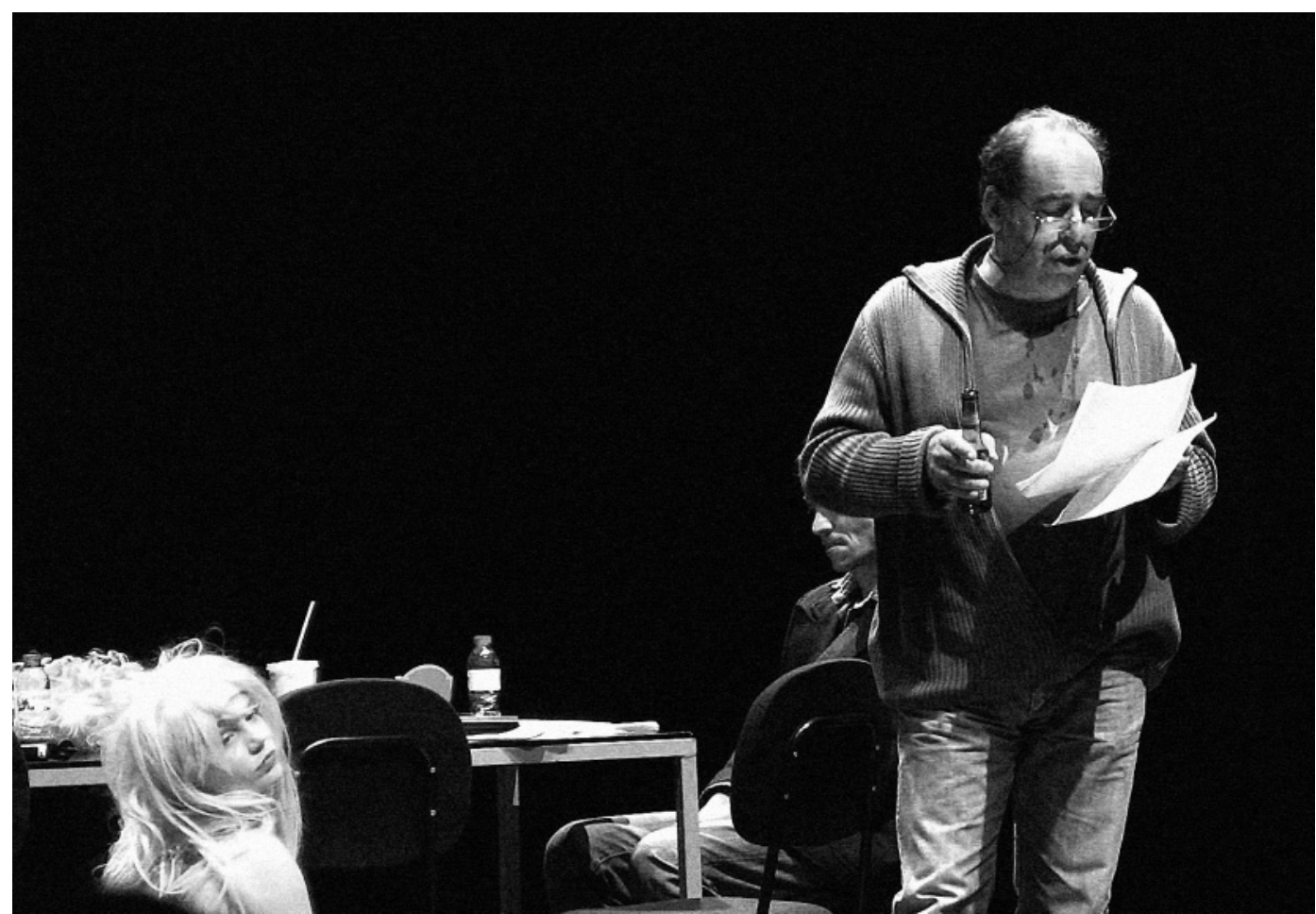

A nossa tradição teatral [...] é profundamente centrada no texto, o que nos leva a ocultar largamente a forma muito singular através da qual o texto se trabalha no teatro. Durante muito tempo, considerou-se que o texto precede o palco e que este chega apenas num segundo movimento. Ora a escrita de palco lembra-nos que, originalmente, tudo se passa da forma exactamente inversa: o texto teatral só se torna fecundo na estreita proximidade do palco e daqueles que o povoam. 0 palco está em primeiro lugar e engendra uma matéria proteiforme, que se torna no próprio texto de teatro, do qual podemos recolher os traços e imaginar que este se torna num livro - uma peça cristalizada num livro. Não podemos nunca esquecer que é o palco que premeia o livro e não o inverso.

Lendo-a, julgo que rapidamente se compreenderá a possibilidade de a encarar como uma das frases-chancela dos Encontros, quer no que diz respeito à sua componente teórico-reflexiva (seminários, conferências e mesasredondas), quer no que diz respeito à componente prática (leituras encenadas e performativas de textos escritos por autores nacionais e estrangeiros).

Fast forward. Estas foram as principais formulaçõesocorrências - aqui compiladas em modo best of - do último seminário dos Encontros, orientado por Carlos J. Pessoa.

Todo o acto de criação é um acto de reparação.

0 Teatro existe onde tudo o resto falha.

A escrita é um diálogo com a terra, mais do que uma auscultação do céu.

Contemporâneo quer dizer com o tempo, estar ou não estar com o tempo... (David Antunes dixit)

Quando tento falar com Deus ao telefone ele está sempre interrompido.

A vida como uma longuíssima paciência.

Os outros autores são os guarda-chuvas que nos protegem do sol.

Contemplar uma caveira é como contemplar uma fotografia.
A filosofia é como um livro policial: anda-se à procura do problema.

Não digo e não deixo de dizer e isso dá-me poder.

Não fazemos nada de original.

Na contemporaneidade o pénis é o radar da sociedade.

As coelhinhas aflitas já tentaram a sua sorte.

Não podemos resolver os problemas, podemos aprender a viver com os problemas.

No final do que foram os Encontros, talvez se possa olhar para estas palavras-ideias e chegar à conclusão que estes constituem alguns dos postulados com que gostariamos de ficar até à próxima edição. To be continued..

\section{Referências bibliográficas}

ADORNO, Theodor / HORKHEIMER, Max (1985), Dialética do esclarecimento: Fragmentos filosóficos, $2^{\text {a }}$ ed., trad. Guido Antonio de Almeida, Rio de Janeiro, Zahar.

BORGES, Vera (2007), O mundo do teatro em Portugal: Profissão de actor organizações e mercado de trabalho, Lisboa, Instituto de Ciências Sociais da Universidade de Lisboa.

DELEUZE, Gilles / GUATTARI, Félix (2003), Kafka: Para uma literatura menor Lisboa, Assirio e Alvim.

OLIVEIRA, Mickael de (2010), Para uma cartografia da criação dramática portuguesa contemporânea [1974-2004]. Tese de Mestrado realizada na Faculdade de Letras da Universidade de Coimbra (texto policopiado).

PHELAN, Peggy (1998), "A ontologia da performance: Representação sem produção", Revista de Comunicação e Linguagens: Dramas, org. Paulo Filipe Monteiro, n. 24, Lisboa, Edições Cosmos, pp. 171-191.

RYNGAERT, Jean-Pierre (1998), "Bernard-Marie Koltès: Sempre detestei um pouco o teatro", Ler o teatro contemporâneo, trad. Andréa Stahael M. da Silva, São Paulo, Martins Fontes, pp. 216-218.

TACKELS, Bruno (2007), Écrivains de plateau, vol. 4, Rodrigo Garcia, Besançon, Les Solitaires Intempestifs. 